\title{
Por que ainda estudar gramática na escola
}

Lorenzo Vitral Universidade Federal de Minas Gerais

\section{Absctract}

This paper presents our proposal for the elaboration of a grammar handbook of Brazilian Portuguese to be used in high schools. First, we make a historical presentation of the debate about the role of grammar in the process of learning/teaching of Brazilian Portuguese as maternal language. Secondly, we explain how our grammar is organized and how one can make good use of it. 


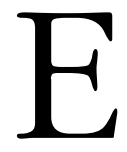

ste artigo traz-nos algumas reflexões que visam a justificar um projeto nosso de elaboração de um manual de gramática destinado a ser um instrumento pedagógico no processo de ensino-aprendizagem de Língua Portuguesa. Esse livro se chamará Sintaxe mínima. Uma proposta de ensino de gramática para o ensino médio e, como seu título o indica, pensamos que o ensino gramatical deve ser concentrado no ensino médio. Do que acabamos de dizer, surgem, naturalmente, várias perguntas:

1. Justifica-se, hoje, escrever uma nova (ou outra) gramática? Já não há tantas?

2. O que essa gramática teria de diferente das demais gramáticas?

3. Se, de acordo com o MEC (Parâmetros Curriculares Nacionais) (MINISTÉRIO DA EDUCAÇÃO, 1998), o objetivo do ensino de Língua Portuguesa é levar o aluno a ter um desempenho satisfatório como leitor e produtor de textos, faz sentido ainda estudar gramática?

Para tentar responder a essas perguntas e justificar nossa proposta, faremos, inicialmente, um breve histórico da discussão sobre o ensino de gramática no Brasil, sobretudo, das causas de seu desprestígio atual; em seguida, falaremos das razões que nos levam a acreditar que a gramática ainda tem um papel relevante no ensino de Língua Portuguesa; e, por último, comentaremos como nosso livro está organizado e como se deve usá-lo.

O debate das últimas décadas acerca do ensino de Língua Portuguesa levou boa parte dos profissionais das áreas de letras e lingüística, principalmente, aqueles que têm "um pé" na Universidade, a se convencer do caráter supérfluo e obsoleto do ensino de gramática 
nos moldes tradicionais. Essa crença tem sido fundamentada, com muita propriedade, por inúmeros trabalhos dos quais se podem destacar os temas seguintes, que são bastantes conhecidos:

(1) Necessidade de elaboração de uma gramática-padrão da língua portuguesa.

(2) Insuficiência dos critérios de análise lingüística empregados pelos manuais tradicionais.

(3) Revalorização de dialetos não contemplados pelos manuais tradicionais.

(4) Mudança de perspectiva em relação à unidade lingüística central no ensino, que passa a ser o texto, e não mais a oração ou o período.

Em relação ao primeiro ponto acima, pode-se mencionar o trabalho de HAUY (1983, p. 5) que, ressaltando, de início, ser o empenho crítico em relação aos manuais tradicionais proveniente, muitas vezes, dos próprios gramáticos tradicionais, demonstra, com farta exemplificação, "o estado caótico em que se encontram nossas gramáticas normativas”. Os aspectos principais de sua argumentação são os seguintes: (a) nenhuma das definições de oração - central, obviamente, na análise sintática - utilizada nos manuais tradicionais é inteiramente adequada; (b) a exemplificação empregada nesses manuais é "muitas vezes errada e isso, em parte, devido às definições que as precedem” (HAUY, 1983, p. 26); (c) há muitas divergências e contradições entre gramáticas e mesmo entre duas obras ou duas passagens numa mesma obra de um único autor, e também (d) diversidade de conceituação e multiplicidade de análise de fatos sintáticos, o que se deixa refletir na nomenclatura exuberante e complexa, inadequada se levarmos em conta que se trata de manuais de ensino.

Esse estado de fatos levou Hauy a recomendar a elaboração de uma gramática-padrão que superasse as dificuldades apontadas e pudesse ser um instrumento válido no ensino de Língua Portuguesa.

Por outro lado, concomitante a isso, fundamentou-se, por meio de perspectivas teóricas desenvolvidas no século XX, uma crítica 
severa aos critérios de análise da Gramática Tradicional, cuja inestimável contribuição foi dimensionada na história, como patrimônio do nosso saber. Trata-se do segundo item acima, que pode ser ilustrado pelo trabalho de PERINI (1985) e que teve como conseqüência adicional lançar dúvidas a respeito da viabilidade do ensino de gramática baseada na perspectiva tradicional, mesmo de posse de uma eventual gramática-padrão, como proposto por Hauy.

No que concerne ao terceiro ponto acima, como é sabido, a revalorização, a partir da década de 70, de dialetos não-padrões do português brasileiro tem sido vista também como um duro golpe ao projeto de ensino baseado no uso de manuais tradicionais. Devido a mudanças sócio-econômicas ocorridas no nosso país a partir da década de 60, a escola fundamental passou a incluir seguimentos sociais que, até então, tinham se mantido à margem da escolarização. Essas classes não dispunham dos meios de acesso à língua veiculada pela Gramática que, como é notório, é aquela de nossos melhores escritores. Esse fator e o campo fértil encontrado pela Sociolingüística nas faculdades brasileiras colaboraram para que fosse relativizado o valor da norma culta entre nós (CASTILHO, 1990).

Além disso, o desenvolvimento das áreas de análise do discurso e da conversação a partir da década de 60 favoreceram mudança de mentalidade em relação ao ensino de língua materna. Ilustrando, assim, o quarto item acima, fez-se "revisão das práticas pedagógicas, provocando o deslocamento do ensino centrado na gramática escolar para o ensino de práticas de linguagem, do ensino que tomava como unidade lingüística a frase para o que toma o texto" (MINISTÉRIO DA EDUCAÇÃO, 1998, p. 3)

Nessa nova visão do ensino de Língua Portuguesa, importa levar o aluno a ser um produtor e receptor competente de textos orais e escritos, pressupondo-se que para ter um bom desempenho em escrita e leitura não é preciso saber teoria gramatical. A hipótese da gramática internalizada ou da existência de um saber gramatical "inconsciente" por parte dos falantes, desenvolvida pela Gramática Gerativa, permitir-nos-ia legitimar essa pressuposição, ou seja, os 
alunos já "sabem gramática" pois se comunicam com perfeição, interpretando e elaborando orações e textos.

Essa mudança de mentalidade em relação ao ensino de língua materna encontra ainda um aliado na constatação de que, até então, não obtivemos êxito na elaboração de um nova gramática, elaborada de acordo com uma nova perspectiva teórica, que venha a substituir os manuais tradicionais, resolvendo ou atenuando, portanto, suas dificuldades. Há tentativas louváveis nesse sentido, como, por exemplo, a gramática de PERINI (1993), cujo uso, contudo, nos parece adequado para o ensino superior, mas não para o ensino médio ou fundamental.

O desestímulo em relação ao ensino de gramática parece-nos, enfim, encontrar apoio na percepção de alguns, nem sempre verbalizada às claras, de que aos alunos de hoje faltam o interesse pela gramática e as condições de seu aprendizado que se viam outrora.

Como justificar, apesar do que acabamos de ver, a elaboração dessa nossa gramática? Não é tarefa fácil, mas creio que há uma "brecha" por onde podemos entrar.

Vamos observar, em primeiro lugar, que, embora esse conjunto de idéias, contrário ao ensino de gramática, viceje em nossas faculdades de Letras durante, pelo menos, as duas últimas décadas, não se conseguiu ainda mudar, substancialmente, a mentalidade da sociedade em geral, que teima em atribuir valor ao ensino gramatical tradicional. Uma das evidências dessa última afirmação é o boom da presença de professores de Português na mídia, que continuam, com vestes modernas, a defender a memorização de exceções de gramática e ortografia, vista com sinônimo de "saber português". Não se trata de avaliarmos agora o valor e a função desses profissionais, mas de interpretar sua crescente atuação como um sinal da importância que a sociedade atribui ao que é suposto se constituir como "saber português".

Pode-se argumentar, no entanto, que a resistência da sociedade é esperada, pois (1) mudanças de mentalidade são efetivamente demoradas, ainda mais tratando-se de uma perspectiva de ensino que se originou há cerca de dois mil anos; e (2) o fato de as pessoas 
pensarem que conhecer "picuinhas" é "saber português" não implica sua validade, ou seja, tratar-se-ia de mais uma ilusão das massas.

Por outro lado, a sobrevivência da perspectiva tradicional e o apego às exceções de gramática podem também indicar que sabemos, de alguma forma, que a familiaridade com os temas gramaticais são relevantes socialmente nas nossas práticas de linguagem. De fato, as pessoas são mais ou menos conscientes de que há vantagens no domínio da norma culta ou português padrão: seu domínio capacitanos a adequar formalmente nossos textos orais e escritos e é nesse registro que estão elaborados textos escritos de todas as épocas, cuja freqüentação nos permite tanto adquirir quanto apreciar conhecimentos. Parece-nos fato, portanto, que, apesar de ter a conseqüência de servir de instrumento de dominação entre classes, a familiaridade com o português padrão possibilita aumento de poder de convencimento das pessoas e conseqüente ascensão social ou profissional. Ora, os manuais gramaticais são reputados como a porta de acesso a esse conhecimento. Daí, portanto, decorre sua valorização social.

É sabido, entretanto, que conhecer a nomenclatura e classificações da Gramática Tradicional tem um papel irrelevante na elaboração de textos do ponto de vista da textualidade. De nada adianta, por exemplo, memorizarmos que hiper-é um prefixo de origem grega e super-é de origem latina na hora de redigir um bom texto, coeso e coerente. Isso depende, seguramente, de outras habilidades cognitivas e também de coisas como: volume de informações, ter o que dizer e, sobretudo, de tempo e trabalho. Estamos de acordo em dizer, então, que saber escrever um texto não é igual a saber gramática no sentido tradicional. Talvez a ilusão das massas de que falávamos seja só essa, ou seja, supor que conhecer exceções e "picuinhas" garanta bons textos orais e escritos.

É bem verdade, por outro lado, que tomar a gramática como objeto de reflexão é útil do ponto de vista da normatização dos textos que elaboramos, o que é imprescindível nas nossas práticas de linguagem. Parece-nos, assim, que a percepção das pessoas das vantagens das "picuinhas" não é de todo infundada. Vejamos um exemplo: quando ocorre posposição do sujeito, prescreve-se que a 
concordância verbal deve realizar-se como aparece em (5 a) abaixo e não como, o que ocorre em dialetos do português do Brasil, em (5b):

(5) a. Saíram da sala os convidados que te chatearam.

b. Saiu da sala os convidados que te chatearam.

Se faz parte do aprendizado de língua portuguesa levar o aluno a reproduzir estruturas como (5 a) em detrimento de (5b), pensamos que ter explicitadas noções como sujeito, verbo e concordância favorece a aquisição dessas estruturas, ou seja, o conhecimento de noções metalingüísticas como essas facilita o emprego da concordância de acordo com o português padrão, o que, é claro, não vai garantir um bom texto, mas assegura sua adequação formal.

Nossa visão dos fatos não é incompatível com a perspectiva de ensino-aprendizagem de Língua Portuguesa que elege o texto como sua unidade. O documento Parâmetros Curriculares Nacionais (op.cit.), que incorpora essa perspectiva, não deixa de reconhecer que há ainda proveito, na prática pedagógica, da reflexão gramatical. É o que se vê, por exemplo, no seguinte trecho:

"O modo de ensinar... não reproduz a clássica metodologia de definição, classificação e exercitação, mas corresponde a uma prática que parte da reflexão produzida pelos alunos mediante a utilização de uma terminologia simples e se aproxima progressivamente, pela mediação do professor, do conhecimento gramatical produzido." (p.29).

Prevê-se, além disso, neste documento, a inclusão, contextualizados nas práticas textuais e de comparação dialetal, de conteúdos gramaticais como os seguintes:

"sistema pronominal...: preenchimento da posição do sujeito, extensão do emprego dos pronomes tônicos na posição de objeto, desaparecimento dos clíticos, emprego dos reflexivos, etc" (p.61)

ou ainda:

"sistema dos tempos verbais (redução do paradigma no vernáculo) e emprego dos tempos verbais (predominância das formas compostas no futuro e no mais que perfeito, emprego do imperfeito pelo 'condicional', predominância do modo indicativo, etc)" (p.61). 
Como se vê, considera-se que não somente não há antagonismo como há proveito em tornar explícitos fatos de gramática, mesmo quando o objetivo precípuo do ensino de língua materna é desenvolver as habilidades de leitura e escrita dos alunos.

Há lugar, portanto, para uma gramática instrumental que nos permita, a partir da gramática interna dos falantes, explicitar fenômenos da língua de maneira a ser o veículo de acesso ao português padrão. Esse manual será fonte de consulta quando, nas práticas textuais, for necessário tomar como referência fatos do português padrão, que será considerado, portanto, como objeto de reflexão na escola.

Mas ensinar que gramática? Que conteúdos? E de que maneira?

Já temos claro que os manuais tradicionais não podem mais servir para acompanhar a reflexão gramatical do dia-a-dia dos alunos. Neste ponto, justifica-se, assim, nosso projeto de elaboração de um manual - chamado de Sintaxe Mínima - que sirva como um livro didático para alunos de ensino médio.

Nosso manual mantém a idéia de que é necessário descrever o código gramatical, tomando-se a oração e o período como limites de análise. Está claro, por conseguinte, que não estamos considerando aspectos formais do texto que poderiam ser reunidos numa bemvinda "gramática do texto" (embora alguns pontos conhecidos da relação entre gramática e texto sejam comentados no apêndice de nosso livro). Uma tal "gramática do texto" é independentemente necessária e sua elaboração, na nossa maneira de ver, não exclui, pelo fato de cada uma ter seu próprio âmbito, a gramática da oração. Nossa Sintaxe Mínima é, então, um manual que visa a servir de instrumento teórico, favorecendo a reflexão de aspectos gramaticais do português padrão.

A elaboração de um manual com essas características exigiu, em primeiro lugar, que se procedesse a uma seleção das informações gramaticais que deveriam compor o livro. Ora, os manuais tradicionais podem ser vistos, na verdade, como um certo tipo de enciclopédia em que se encontram, além dos conteúdos relativos aos aspectos 
sonoros, morfológicos, semânticos e sintáticos da língua, informações acerca de grafia correta, de dialetologia, da evolução histórica da língua, de versificação, etc. Foi feita, então, uma triagem de conteúdos, levando-se em conta, como critério, a relevância do tema na aquisição do português padrão, cujo emprego em textos, como já dissemos, é o que se almeja dos alunos.

Chegamos à conclusão de que basta uma sintaxe ou uma morfo-sintaxe da língua portuguesa para instrumentalizar a reflexão gramatical no ensino médio, considerando-se que a aquisição e o treinamento ortográfico, o que inclui noções como silabificação, acentuação, etc., já se realizaram no ensino fundamental.

Em segundo lugar, colocou-se a questão da definição do quadro teórico para a descrição das noções gramaticais que nos interessavam. Pensamos que não vale a pena não levar em conta entidades teóricas da Gramática Tradicional, como, por exemplo, as previstas pelas noções de classe e função, além de sua nomenclatura para designá-las. Adotamos, portanto, grande parte do aparato descritivo da Gramática Tradicional, tendo a preocupação de (1) usar de maneira inequívoca os critérios de análise formal e semântico; (2) distinguir regras de exceções; (3) racionalizar a nomenclatura tradicional, condensando noções cuja diferenciação não foi julgada relevante em relação aos objetivos do nosso manual.

Além disso, foi necessário também levar em conta certas concepções oriundas de correntes lingüísticas do século passado. Introduzimos, por exemplo, as noções de (1) sintagma que, como se sabe, é o constituinte que desempenha as funções de sujeito, complemento e modificador, e é necessária à definição da oração; (2) papéis temáticos, que nos permitiu precisar a interpretação dos constituintes que desempenham as funções que acabamos de mencionar; e a de categoria vazia, oriunda da Gramática Gerativa, que foi empregada na descrição do chamado sujeito elíptico e na definição de oração. Nós retomamos igualmente uma noção tradicional que é pouco explorada nos manuais tradicionais. Trata-se da distinção entre categorias lexicais e gramaticais, que é importante na definição formal da oração. 
Definido o quadro teórico, que, na verdade, não é homogêneo, e selecionados os conteúdos, colocou-se a questão de como expor esses conteúdos de maneira didaticamente interessante.

Pensamos que uma das grandes dificuldades dos manuais tradicionais, do ponto de vista didático, seja o fato de que nem sempre fica claro para quem consulta um manual tradicional quando estão sendo descritos aspectos da língua que ocorrem sempre, isto é, tratáveis através de regras; e quando se está falando de exceções a essas regras. As exceções constituem boa parte dos conteúdos desses manuais e, apresentadas de forma conjunta com as regras, produzem, no meu modo de ver, um efeito pernicioso que é favorecer a "decoreba", isto é, a memorização de informações, que são acumuladas sem reflexão. Em outras palavras, a própria apresentação dos conteúdos pelos manuais tradicionais impede sua fixação. Sim, porque sabemos que quem decora algo o esquece.

A solução pensada para esse problema foi a seguinte: separar o manual em duas partes. A primeira, chamei de REGRAS PRINCIPAIS e a segunda de REGRAS SECUNDÁRIAS. Fazem parte da primeira parte apenas aqueles aspectos da gramática da língua que são gerais, que são mais freqüentes; e estão na segunda parte aqueles conteúdos que são menos freqüentes, as exceções e os casos que podem ser considerados duvidosos. Essa segunda parte está organizada na forma de um glossário, o que significa que ela deve ser usada como fonte de consulta, evitando-se, portanto, a memorização. A rigor então os alunos devem estudar ou tomar como reflexão, apenas a primeira parte do livro. Nessa primeira parte, há links com a segunda, de forma que, quando ocorrer uma dúvida em relação a um assunto, o aluno deverá consultar a segunda parte para resolvê-la.

Por exemplo: em relação ao fenômeno da colocação pronominal, que é tratado na seção chamada de Alterações da Ordem Básica, foi fornecida, na primeira parte do livro, a informação de que o pronome fraco é empregado, na língua culta, depois do verbo, e na segunda parte, no glossário gramatical, foram listados os ambientes em que o pronome é atraído para antes do verbo, isto é, quando há 
(1) palavras de sentido negativo, (2) advérbios como aqui, ali, já, (3) conjunções como porque, que, quando, (4) pronomes relativos e (5) pronomes interrogativos. Por fim, apresentamos (6) as particularidades de colocação quando temos um auxiliar mais gerúndio, particípio ou infinitivo.

A vantagem dessa forma de organização do material é reduzir a necessidade da memorização, ou seja, os alunos podem estudar a primeira parte do livro de forma reflexiva, mais dedutiva e menos indutiva, e utilizar a segunda parte como se faz com um dicionário.

Por fim, simplificamos ao máximo a nomenclatura tradicional, valendo-nos do conhecimento gramatical internalizado do aluno.

Passamos a seguir a dar ao leitor uma idéia dos conteúdos do nosso manual.

A primeira parte do livro, AS REGRAS PRINCIPAIS, foi dividida em 4 seções que são as seguintes: (1) Categorias e Sintagmas; (2) Papéis Sintáticos; (3) Classes de Verbos; e (4) Ordem Básica e Alterações da Ordem Básica.

Na primeira seção, Categorias e Sintagmas, distinguem-se dois tipos de categorias sintáticas: as categorias lexicais e as categorias gramaticais. Essa distinção é importante porque nos permite dizer que a oração, do ponto de vista formal, é a junção dos dois tipos de categorias. Nessa seção, a definição dessas categorias foi feita apenas através de critério formal, isto é, leva-se em conta somente a distribuição dos itens na oração e suas características morfológicas.

Destacamos cinco categorias lexicais, que são as seguintes: verbo, nome, adjetivo, advérbio e preposição. O que há de diferente entre nossa terminologia e a nomenclatura da NGB é o uso de nome em lugar de substantivo: nome parece-nos mais transparente e é compatível com a terminologia de Sintagma Nominal, igualmente utilizada.

Definimos também quatro categorias gramaticais, a saber, determinante, pronome, flexão verbal e conjunção. A classe dos determinantes reúne os artigos definidos e indefinidos, os pronomes indefinidos e os demonstrativos. Em relação aos pronomes, não 
pudemos deixar de distinguir três subtipos: os pronomes pessoais, pronomes possessivos e os pronomes interrogativos e relativos. Apartamos também a classe da flexão da classe do verbo, alertando para o fato de que, diferentemente das outras, a flexão, do ponto de vista da emissão sonora, não forma, sozinha, uma palavra.

Foi feita uma simplificação nos paradigmas flexionais a fim de permitir-lhes refletir o uso real no português do Brasil atual. Excluímos, assim, a segunda pessoa do plural vós e mantivemos a segunda pessoa do singular $t u$, mas conjugada de acordo com as terminações da terceira pessoa do singular. Estudos recentes mostram que, mesmo na região sul, o uso de $t u$ conjugado na segunda pessoa do singular é muito mais restrito do que se imagina.

Distinguimos as conjunções subordinativas das coordenativas e definimos orações subordinadas e coordenadas, valendo-nos do critério de que as primeiras, mas não as segundas, desempenham as funções de sujeito, complemento e modificador.

Enfim, é apresentada nessa seção a noção de sintagma, cuja inclusão se deve ao fato de que, como se sabe, são esses constituintes que desempenham as funções sintáticas. Por essa razão também, inserimos apenas com os sintagmas formados pelas categorias lexicais, isto é, os sintagmas nominal, verbal, adjetival, preposicional, e adverbial. Haveria a possibilidade igualmente de incluir os sintagmas formados pelas categorias gramaticais. É o que se faz na Gramática Gerativa hoje em dia. Mas, como a definição das funções sintáticas desses sintagmas é muito menos clara, avaliamos que não haveria ganho do ponto de vista dos nossos objetivos.

Na segunda seção da primeira parte do livro, isto é, Papéis Sintáticos, falamos da parte da sintaxe da língua que é determinada semanticamente. Levam-se em conta as funções de Sujeito, Complemento e Modificador, que são chamadas de papéis sintáticos. O termo papel parece-nos, como se verá, didaticamente mais útil que a expressão função, que é por demais abrangente e obscura.

Em relação à identificação dos sintagmas que desempenham os papéis sintáticos, utilizamos a proposta de que, para interpretarmos 
e identificarmos os papéis sintáticos, empregamos alguns critérios, aplicados, provavelmente, de maneira conjunta. Trata-se dos seguintes critérios: (1) a concordância, isto é, o sintagma concorda ou não com o verbo, (2) a posição do sintagma na oração e (3) a interpretação do sintagma.

No que concerne à interpretação, são descritos os conteúdos semânticos que os sintagmas, que desempenham os papéis de sujeito, complemento e modificador, podem assumir na oração. Trata-se então de explicitar como os sintagmas participam do evento determinado pelo verbo da oração. O sujeito, por exemplo, pode ser interpretado, principalmente, como agente, paciente, causa, instrumento, experienciador, destinatário e possuidor.

Acreditamos que vale a pena incluir esse tipo de informação num manual escolar. Nossa crença se deve às seguintes razões: (1) são noções altamente intuitivas, fazendo uso da "gramática interna" do falante, (2) favorecem a tomada da gramática por parte do aluno como objeto de reflexão e (3) podem auxiliar no desenvolvimento da capacidade de elaboração textual dos alunos na medida em que os levam a tomar consciência de que a oração faz referência a eventos que se passam no mundo e que a descrição desses eventos é determinada pelos verbos, que estabelecem o modo da contribuição semântica dos sintagmas. Esses eventos, estabelecidos pelos verbos, podem indicar, de acordo com a nossa descrição, sobretudo, estados, processos, ações, existência e fenômenos da natureza.

A respeito ainda da identificação do sujeito, pareceu-nos necessário distinguir subcasos desse papel sintático, como, aliás, também o faz a GT. O primeiro problema que surgiu, foi como lidar com o chamado sujeito elíptico ou oculto. Optamos por trazer, para um manual escolar, algumas conquistas teóricas da lingüística moderna, mais especificamente, da Gramática Gerativa.

Essa teoria trabalha com a idéia de que a "gramática interna" da mente tem três componentes: os componentes sintático, fonético e semântico, e que o componente sintático é que permite a associação entre os componentes fonético e semântico. Na maioria 
das vezes, uma palavra empregada numa oração - por exemplo, João, na oração João acaba de chegar-, tem existência sintática: no caso é o sujeito; tem existência fonética: João foi pronunciado; e tem existência semântica: João foi interpretado: sabemos que é um ser humano e vamos supor, além disso, que é meu vizinho, etc. Entretanto, a Gramática Gerativa propõe que nem sempre é assim, isto é, parece existirem constituintes da língua que podem não ter existência em todos os três componentes. É o caso, por exemplo, do pronome it do inglês quando aparece em orações como It rains, que é traduzido por chove. Nesta oração, it tem existência sintática: é sujeito; fonética: foi pronunciado; mas não semântica: it, nesse contexto, não significa nada. Por isso, ele é chamado de expletivo. O contrário também parece existir, isto é, um constituinte que tem existência sintática e semântica mas não fonética. Essa é a análise que é proposta para o fenômeno do sujeito elíptico em línguas de flexão rica como o italiano, espanhol e português. Assim, em orações como Saímos ontem, propõe-se que há um sujeito, que pode ser recuperado pela flexão verbal, isto é, trata-se de um pronome de $1^{\text {a }}$ pessoa do plural, que é vazio foneticamente ou, simplesmente, não tem existência no componente fonético. Por essa razão, vamos chamálo de Sujeito Não-Pronunciado. Essa análise é, na realidade, apenas uma elaboração mais rigorosa da intuição da GT.

Entretanto, vamos diferir muito da GT na análise das construções chamadas de orações sem sujeito. Essas orações sempre foram um dos grandes problemas das análises tradicionais porque inviabilizam toda definição de oração, baseadas, normalmente, nas noções de sujeito e predicado. HAUY (1983, cap. 1) demonstra o que acabo de afirmar comentando as várias definições de oração da GT e argumentando que todas esbarram na definição das orações sem sujeito. Há uma falsa solução que consiste em dizer que há orações formadas apenas com predicado, o que equivale a jogar fora a noção de predicação.

O que fizemos então foi mostrar, inicialmente, que, quando temos orações como Choveu muito ou Há cadeiras na sala, consideradas 
pela GT como sem sujeito, têm-se, na verdade, descrições de eventos em que não há um agente praticando nenhuma ação, nenhum paciente recebendo ação, etc. Quer dizer, são eventos relativos a fatos da natureza, atestação de existência, marcação de tempo e assim por diante. Mas se, por outro lado, formos olhar essas orações do ponto de vista da forma, vê-se que o verbo está flexionado na terceira pessoa do singular. O que consideramos, então, é que há um sujeito sim nessas orações e que ele é vazio foneticamente, como aquele que aparece em Saímos ontem, mas diferentemente deste caso, em orações como Choveu ontem, o sujeito é não pronunciado e não interpretado. Ele é não interpretado porque não há um constituinte funcionando como agente, paciente, possuidor, etc.

Essas idéias podem, à primeira vista, parecer difíceis e inadequadas para um manual como o nosso. Pensamos, contudo, que não e apresentamos as seguintes razões:

(1) Essas propostas estão expostas numa linguagem muito simples e com o auxílio de metáforas para ajudar a compreensão.

(2) As informações apresentadas decorrem umas das outras, ou seja, é possível aprender o assunto de forma dedutiva. A comparação feita com outras línguas como o inglês e o português de Portugal também permite a reflexão e favorece a compreensão das propostas.

(3) Pensamos que é preciso trazer, para um público maior, progressos teóricos, que só são discutidos normalmente em nível de terceiro grau. As novidades podem parecer difíceis num primeiro momento mas, se forem coerentes, poderão se firmar na escola.

(4) A análise baseada na idéia de categoria vazia foneticamente não é completamente ad hoc, isto é, válida apenas para o caso do sujeito. Ela é apropriada também para outros fenômenos, como por exemplo, os casos de objeto não pronunciado que ocorre em respostas a perguntas, como por exemplo, a resposta Eu vi a perguntas como Você viu o João?; e também para os casos de elipses de verbos ou predicados conhecidos, na GT, como zeugma. 
Por fim, outra vantagem da nossa análise é que permite definir a oração como o enunciado que sempre apresenta sintagma nominal e sintagma verbal, podendo esses constituintes ser pronunciados ou não.

Nessa seção 2, falamos ainda da identificação do complemento e do modificador. Utilizamos o termo complemento e não objeto a fim de poder incluir os casos de complemento nominal e de preposição. Os critérios são os mesmos empregados para o sujeito: o da concordância, nesses casos usados negativamente, isto é, o complemento e o modificador não concordam com o verbo; a posição na oração e a interpretação do sintagma. Uma questão importante é a distinção, sempre problemática, entre modificador e complemento. Para resolvêla, apelamos para duas noções: um constituinte pode ser exigido do ponto de vista do discurso, isto é, da intenção comunicativa do falante; ou ser exigido do ponto de vista da sintaxe, ou seja, o falante é obrigado a empregar o constituinte porque algum outro termo assim o exige. No primeiro caso, trata-se dos modificadores e no segundo caso trata-se dos complementos. Note-se que, mesmo no caso em que o complemento é não-pronunciado, na nossa perspectiva, sempre existe um complemento. Ou, em outras palavras, não há casos de termos transitivos que apareçam sem seus complementos.

Na seção 3, chamada de Classes de verbos, destacamos o verbo como o termo mais importante da oração porque ele determina (1) os tipos de eventos - e, de acordo com os eventos, são determinados os modos de participação dos constituintes que desempenham os papéis de sujeito e complemento; (2) a presença ou ausência de complementos; e (3) os tipos de sintagmas e orações que podem ser complementos. Esses três itens são três subseções dessa seção, em que, como se percebeu, estamos discutindo, mas sem usar a terminologia tradicional, as noções de regência e transitividade.

Na primeira subseção, como já vimos, é feita uma descrição semântica de eventos como sendo, sobretudo, processos, estados, ações, existência e fenômenos da natureza. Distinguem-se, na segunda subseção, os seguintes tipos de verbos 1) verbos que não 
aceitam complementos, 2) verbos que exigem complementos, e 3) verbos que podem ou não dispor de complemento pronunciado. Nesse último caso, trata-se de uma classe distinta de verbos que não depende de um contexto discursivo para permitir objetos não pronunciados. Por exemplo: Fumaça incomoda; Esse cachorro morde, etc. Enfim, na subseção 3, diferenciamos os seguintes tipos de verbos: 1) verbos que admitem apenas um sintagma nominal como complemento, 2) verbos que aceitam, ao mesmo tempo, um sintagma nominal e um sintagma preposicional como complementos, 3) verbos que aceitam um sintagma nominal ou uma oração como complemento, 4) verbos que admitem, como complemento, um sintagma preposicional ou uma oração, e 5) verbos que aceitam um sintagma preposicional e uma oração interrogativa com complemento.

Na seção 4, nomeada de Ordem Básica e Alterações da Ordem Básica, tratamos do fenômeno da colocação utilizando a idéia de ordem básica e suas variações. Assim, comentamos que a ordem de palavras mais freqüente no português é SVC, isto é, Sujeito-VerboComplemento, e por isso é a ordem básica da nossa língua. Entretanto, não é a única possível. São listadas então as seguintes alterações da ordem básica:

1. O sujeito pode aparecer no final da oração, o que nos dá a ordem VOS ou VS.

2. O complemento pode aparecer 1) no início de oração, o que permite a ordem CSV. Para ilustrar esse caso, utilizamos as orações interrogativas, as orações com topicalização e as orações relativas; e 2) entre o sujeito e o verbo quando está na forma pronominal fraca, isto é, átona, o que nos dá a ordem SCV.

Essa é a primeira parte do livro.

A segunda parte, como já dissemos, contém AS REGRAS SECUNDÁRIAS. É como um glossário gramatical em que são listadas as exceções, os casos menos freqüentes e particularidades previstas pelos temas abordados na primeira parte do livro. Por exemplo, em relação à flexão verbal, nessa segunda parte, foram definidos e 
apresentados os paradigmas de conjugação dos verbos irregulares, abundantes, defectivos, pronominais e auxiliares.

Nosso livro apresenta ainda um APÊNDICE que trata das relações entre gramática e texto. São comentados os recursos de que dispomos, do ponto de vista da sintaxe, para articular de maneira coesa as orações do texto. Introduzem-se os seguintes temas, que são bem conhecidos:

A) As conjunções simples e compostas. Trata-se de um comentário do valor das conjunções e dos papel delas na coesão textual, baseado no trabalho de PLATÃO \& FIORIN (1992).

B) O determinante definido e os pronomes. Falamos sobre o papel anafórico desse itens no texto e também sobre alguns problemas de redação causados pelo uso indevido desses itens. Nessa última parte, valemo-nos do livro de BASTOS \& MATTOS (1986).

C) A correlação de tempos verbais. Nessa parte, também baseada em PLATÃO \& FIORIN (1992), comenta-se como é feita a articulação de tempos verbais entre orações, ou seja, não basta fornecer o paradigma de conjugação verbal mas também mostrar como os tempos podem ser correlacionados no texto.

D) A necessidade da presença de complementos e modificadores. Trata-se de um problema comum em redações, causado, sobretudo, pela influência da oralidade: a ausência desses constituintes em textos escolares, provocando incompletude e imprecisão da mensagem. Nesse tema, levamos em conta os trabalhos de STARLING (1990) e GARCIA (1973).

Por fim, algumas palavras acerca dos exercícios previstos para esse livro. Estamos de acordo com a idéia de que os exercícios tradicionais, como os de substituição, desvinculados do uso real de língua, tem eficácia limitada. Elaboramos assim exercícios que levassem o aluno a refletir sobre noções metalingüísticas e sobre a adequação formal de textos. Utilizamos, na maior parte das vezes, exercícios de revisão de textos, que foram extraídos, majoritariamente, de jornais e revistas atuais. 


\section{REFERÊNCIAS BIBLIOGRÁFICAS}

BASTOS, L. K.; MATTOS, M. A. de. A produção escrita e a gramática. São Paulo: Martins Fontes, 1986.

CASTILHO, A. Variação lingüística, norma culta e ensino de lingua materna. São Paulo: Secretaria do Estado da Educação, 1978.

. Português falado e ensino da gramática. Letras de Hoje, Porto Alegre, v. 25, n. 1, p.106-36, 1990.

GARCIA, O. Comunicação em prosa moderna. Rio de Janeiro: Fundação Getúlio Vargas, 1973.

HAUY, A. Da necessidade de uma gramática-padrão da língua portuguesa. São Paulo: Ática, 1983.

MINISTÉRIO DA EDUCAÇÃO E CULTURA. Parâmetros Curriculares Nacionais. Terceiro e Quarto Ciclos do Ensino Fundamental. Língua Portuguesa, Brasília,1998. PERINI, M. Para uma nova gramática do português. São Paulo: Ática, 1985. . Gramática descritiva do português. São Paulo: Ática, 1993.

PLATÃO \& FIORIN. Para entender o texto - Leitura e redação. São Paulo: Ática, 1992.

STARLING, M. H. Interferência da lingua oral no processo de estruturação da escrita escolar. 1990. Dissertação (Mestrado em Estudos Lingüísticos) Universidade Federal de Minas Gerais, Belo Horizonte.

VITRAL, L. Sintaxe mínima. Uma proposta de ensino de gramática para o ensino médio. Belo Horizonte: UFMG. (Em preparação). 